УДК 576.8.097.29

\title{
STUDY OF TOLERANCE OF ENTEROBACTERIA TO CHLORINE-BASED BIOCIDES IN EXPERIMENTAL MODELS USING CHROMOGENIC INDICATOR TESTS
}

\author{
N.R. Efimochkina, I.B. Bykova, Yu.V. Korotkevich, Yu.M. Markova, \\ L.P. Minaeva, S.A. Sheveleva
}

FSBI "Institute of Nutrition", Russian Federation, Moscow, 2/14 Ustinsky Passage, 109240

\begin{abstract}
The species-specific composition of microbial contaminants of vegetable raw materials and equipment used in the production of biotechnological products and beverages fermentation are studied. 85 enterobacteria strains was isolated and investigated, 46 strains of the genera Enterobacter, Pantoea, Citrobacter, Serratia, Escherichia, Cronobacter was identified to the species level; the most frequently detected bacteria of the genera Enterobacter and Pantoea (about $50 \%$ ). For the first time developed and tested chromogenic in vitro model based that allows to quantify the degree of inhibition of gram-negative microflora under the influence of antimicrobial agents depending on the concentrations of biocides and density of bacterial populations. A comparative analysis of the tolerance of Enterobacteriaceae strains from different biotopes was conducted. Sensitivity to the treatment of chlorine-containing biocides in 26 strains of enterobacteria from plant material and 9 strains of Escherichia coli from the intestine of male rats of Wistar line was tested. Enterobacteria from vegetable raw materials and swabs were more resistant to antimicrobial action of chlorine, than the representatives of the populations of the normal intestinal microbiota. It is established that the active chlorine concentration of $50-100 \mathrm{mg} / \mathrm{dm}^{3}$, the most commonly used in the processing of vegetable raw materials, is not effective for Enterobacteriaceae, if the density of the microbial population is $10^{5-7} \mathrm{cells} / \mathrm{cm}^{3}$ and above. At an initial level of contamination with Enterobacteriaceae not more than $10^{3} \mathrm{cells} / \mathrm{cm}^{3} \mathrm{pro}-$ cessing solutions with a concentration of active chlorine of 75 to $100 \mathrm{mg} / \mathrm{dm}^{3}$ can provide effective disinfection of raw materials, equipment, or inventory. Experimental chromogenic in vitro model proposed to assess the impact of chlorine-based biocides on the degree of the enterobacteria inhibition, can be used to justify the selection and doses of antimicrobial agents, effective against other groups of microbial contaminants. This will optimize the use of modes of decontamination of raw materials and sanitizing equipment in the food industry.
\end{abstract}

Key words: enterobacteria, chromogenic model in vitro, vegetable raw materials, chlorine-based biocides, tolerance.

Current development theories behind the mechanisms of bacterial pathogenicity which ensure the interaction of the agent with the environment in corresponding ecological niches and communicate tolerance to unfavorable conditions of the surrounding environment are the basis for the development of new approaches to the study of behavior of food bacterial pathogens under exposure to physio-chemical, technological and other food production and storage parameters.

The adverse impact of the external environment on the viral functions of a bacterial cell takes place on various regulatory levels which may result in the development of induced tolerance of microorganisms to the impact of various bacterial factors.

In the wild as well as during sanitary water processing or equipment disinfection, tolerance of bacteria may be formed when affected by various anti-bacterial agents including chlorine, acids, alkalis, preservatives, antioxidants, bacteriophages colicins, acrylates, metal ions $[1,7,12]$.

Today chlorine-bearing products are widely used in food industry to decrease the seeding of

(C) Efimochkina N.R., Bykova I.B., Korotkevich Yu.V., Markova Yu.M., Minaeva L.P., Sheveleva S.A., 2015

Efimochkina Natalia Ramazanovna - Doctor of biological sciences, leading research worker of the Laboratory of biosafety and nutrimicrobiom analysis (e-mail: karlikanova@ion.ru; tel. 8 (495) 698-53-83; 8 (915) 366-62-59).

Bykova Irina Borisovna - research worker of the Laboratory of biosafety and nutrimicrobiom analysis (e-mail: bykova@ion.ru; tel. 8 (495) 698-53-83).

Korotkevich Yulia Vladimirovna - junior research worker of the Laboratory of biosafety and nutrimicrobiom analysis (e-mail: ulya_korotkevich@ mail.ru; tel. 8 (495) 698-53-83).

Markova Yulia Mikhailovna - junior research worker of the Laboratory of biosafety and nutrimicrobiom analysis (e-mail: yulia.markova.ion@gmail.com; tel. 8 (495) 698-53-83).

Minaeva Liudmila Pavlovna - Candidate of technical sciences, leading research worker of the Laboratory of biosafety and nutrimicrobiom analysis (e-mail: Liuminaeva-ion@mail.ru; tel. 8 (495) 698-53-83).

Sheveleva Svetlana Anatolievna - Doctor of biological sciences, head of the Laboratory of biosafety and nutrimicrobiom analysis (e-mail: sheveleva@ion.ru; tel. 8 (495) 698-53-83). 
pathogenic microorganisms $[9,10,11,13]$. Free chlorine and the compounds from which it is produced (sodium hypochlorite, calcium, magnesium, chloride of lime, chloramine, chlorine dioxide, sodium dichloroisocyanurate and potassium dichloroisocyanurate) have a high antimicrobial power against most pathogenic microorganisms and are widely used as disinfectants in medicine and veterinary medicine, drinking water decontaminant, wastewater purifier as well as in the production of food products for equipment treatment and decreased microbial contamination of the used raw materials.

Treatment with chlorine-bearing biocides protects the products from cross-seeding of the food infection agents and toxic infection, and extends shelf life of the products. However the use of chlorine is associated with a number of adverse effects including the formation of trihalomethanes that demonstrate toxic and carcinogenic activity: chloroform dihlorbrommetana, dibromochloromethane and bromoform $[4,5,6,8]$. Overall, observance of the maximum permissible levels helps avoid direct health risks such as toxic, allergic and other reactions caused by food products and drinks with residues of those substances. Recently, however, it has been proved that microorganisms - food and drink contaminants - can possible develop hyposensitivity to biocides as well as tolerance to medical antimicrobial agents [11]. Biocides are also associated with such adverse consequences as accelerated evolution of bacterial pathogens and development of new infections that are hazardous to humans [1].

The prevalence of these effects indicates that the delayed risks associated with the use of antimicrobial products for industrial purposes are underestimated. Such topics as safety of traditional concentrations of biocides used in the food industry, development of tolerance towards them in various contaminants, alternation of phenotypic characters of the most important groups of microorganisms are underexplored.

To reduce the risk of adverse effects associated with the use of active chlorine, it is important to validate the selection of effective concentrations of working solutions of chlorine-bearing products and improve the modes of decontamination of raw materials and sanitary treatment of equipment used at food enterprises.

Therefore, we conducted an assessment of the sensitivity of microorganisms - contaminants of biotechnological food facilities - to chlorine and chlorine bearing products based on the selection of optimum concentrations and technological modes of chlorination for the purpose of inhibiting the growth or destroying bacteria of the family Enterobacteriaceae.

For the purposes of the study, we developed an experimental chromogenic model for in vitro assessment of the degree of inhibition of gramnegative microbial flora under the impact to chlorine-containing biocides which makes it possible to make a quantitative evaluation of the sensitivity of enterobacteria to antimicrobial treatment depending on chlorine concentrations and density of bacterial populations.

\section{Materials and methods.}

Assessment of the health impact of chlorinecontaining substances was conducted with the use of various concentrations of active chlorine solutions and suspensions of enterobacteria teststrains. Effectiveness of antimicrobial power of chlorine was evaluated by the presence or absence of growth of the strains in glucose-peptone medium (GPM) after introducing chlorine and 18 hours of culture samples at 37C. As a control, the same dilution test culture was used without the addition of chlorine, and samples with uninoculated medium GPM.

To analyze the possibility of variation of the two factors - chlorine concentration and density of bacterial suspension - we used 96-well sterile immunology plates with the working volume of $200 \mu \mathrm{L}$ per well.

At first, we filled all the plate wells with $180 \mu \mathrm{L}$ of sterile GPM; then we introduced $20 \mu \mathrm{L}$ of the daily suspension of test-strains with the help of 8-channel metering unit $\left(10^{9}-10^{11}\right.$ cells $\left./ \mathrm{cm}^{3}\right)$ to obtain the first ten-fold dilution; similarly, the culture was tittered to the $11^{\text {th }}$ ten-fold dilution. The twelfth vertical row was used as a negative control. To the horizontal rows of wells, we added equal amounts of percent active chlorine to obtain the predicted concentration in the medium from 200 to $10 \mathrm{mg} / \mathrm{dm}^{3}$. We did not add active chlorine to the last row of the plate $(\mathrm{H})$.

During the visual assessment of the growth of test-strains, we added bromothymol blue indicator solution to the GPM medium $\left(2 \mathrm{~cm}^{3} 1.6 \%\right.$ alcoholic solution of the indicator per $1 \mathrm{dm}^{3}$ of the medium). Turbidity of the medium and the change of color from blue-green to yellow indicated growth. The optical density of the medium was measured with the help of Sunrise filter photometer, wavelength: $450 \mathrm{~nm}$.

The qualitative assessment of the sensitivity of Enterobacter strains to chlorine was conducted 
by determining the degree of growth inhibition of test-strains depending on the dose of active chlorine and original density of the population which was expressed as the difference in titers (number of wells with the signs of growths)in the control and experimental plate rows:

$$
\Delta i=T_{K}-T_{N},
$$

where $T_{K}$ is the titer of culture without chlorine, $T_{N}$ is the titer of culture with a corresponding chlorine dose $(\mathrm{N})$.

We used a disinfectant that contains gramevin as a chlorine-containing agent. The working solutions with various concentrations of active chlorines were used immediately before the experiment.

For the model, we used the following teststrains : Salmonella enteritidis 874 provided by the Nutrition Research Institute, S.typhimurium NCTC 00074 and Escherichia coli 1330 serotype O157:H7 provided by Tarasevich State Research Institute. The objects of the research in chromogenic models in vitro were Enterobacteriaceae bacteria strains produced from plant raw materials (potatoes, grains, malt) and wipe samples from brewing equipment.

The species of isolated Enterobacter strains were determined with the help of biochemical test systems API 20E, Rapid 20E, API 10S, (BioMerieux, France). Additionally, for the model test objects, we used E.coli strains isolated from the intestines of laboratory animals (Wister male rats). The specific species of the strains was determined with the use of biochemical test systems API 20E, Rapid 20E, API 10S, (Bio-Merieux, France). Overall, 87 enterobacteria cultures were tested during the experiment.

\section{Results}

The design of the 2-factor model experiment with the testing of the collection strain E.coli 1330 is presented in Table 1 below. In in vitro experiment, it was found that the active chlorine concentrations of 50 and $100 \mathrm{mg} / \mathrm{dm}^{3}$ which are most frequently used for decontamination of the drinking water and treatment of plant raw materials are not effective against the pathogenic bacteria of family Enterobacteriaceae if the density of microbial population totals more than $1 \times 10^{7}-5 \times 10^{7}$ cells $/ \mathrm{cm}^{3}$. At the same time, Salmonella survived the input concentration $10^{5}-10^{6}$ cells $/ \mathrm{cm}^{3}$ (Figure 1).

We used a chromogenic model to analyze the density of E-coli test-strains isolated from the normal intestinal microbial flora of laboratory animals to chlorine. To conduct the study, we selected 9 typical E.coli strains identified by the battery of culture and biochemical tests on API 10S. The tolerance of E.coli cultures isolated from the microbial flora of laboratory animals to chlorine action (see Table 3) was compatible with the sensitivity of the collection strain E.coli of the serotype O157:H7, whereas the degree of inhibition of salmonella in the same conditions was significantly lower (see Table 2).

This in vitro experiment showed that active chlorine in the concentration of $150-200 \mathrm{mg} / \mathrm{dm}^{3}$ has s strong bactericidal activity against E.coli resulting in virtually complete inactivation of living cells in the concentration of less than $10^{8}$ $\mathrm{CFU} / \mathrm{cm}^{3}$. Active chlorine in the concentration of $75-100 \mathrm{mg} / \mathrm{dm}^{3}$ reduces the amount of living cells by 1.1-2.7 orders; active chlorine in the concentration of $50 \mathrm{mg} / \mathrm{dm}^{3}$ had little effect against the bacterial suspension of any density.

Table 1

Assessment of the chlorine impact on Escherichia coli 1330

\begin{tabular}{|c|c|c|c|c|c|c|c|c|c|c|c|c|}
\hline \multirow{2}{*}{$\begin{array}{c}\text { Doses of active } \\
\text { chlorine, } \mathrm{mg} / \mathrm{dm}^{3}\end{array}$} & $1 \mathrm{p}$ & $2 \mathrm{p}$ & $3 \mathrm{p}$ & $4 \mathrm{p}$ & $5 \mathrm{p}$ & $6 \mathrm{p}$ & $7 \mathrm{p}$ & $8 \mathrm{p}$ & $9 \mathrm{p}$ & $10 \mathrm{p}$ & $11 \mathrm{p}$ & OK \\
\hline & 0.495 & 0.492 & 0.424 & 0.416 & 0.426 & 0.405 & 0.412 & 0.420 & 0.414 & 0.417 & 0.412 & 0.460 \\
\hline 200 & 1.120 & 0.480 & 0.395 & 0.388 & 0.392 & 0.385 & 0.392 & 0.391 & 0.413 & 0.404 & 0.396 & 0.442 \\
\hline 150 & 0.965 & 0.805 & 0.381 & 0.346 & 0.352 & 0.360 & 0.337 & 0.349 & 0.354 & 0.359 & 0.351 & 0.370 \\
\hline 100 & 1.089 & 0.889 & 0.376 & 0.336 & 0.345 & 0.342 & 0.339 & 0.345 & 0.334 & 0.332 & 0.324 & 0.364 \\
\hline 75 & 1.051 & 0.828 & 0.589 & 0.341 & 0.356 & 0.338 & 0.330 & 0.325 & 0.321 & 0.309 & 0.306 & 0.335 \\
\hline 50 & 0.954 & 0.710 & 0.652 & 0.627 & 0.612 & 0.598 & 0.323 & 0.394 & 0.301 & 0.290 & 0.287 & 0.315 \\
\hline 25 & 0.908 & 0.745 & 0.625 & 0.620 & 0.641 & 0.619 & 0.613 & 0.642 & 0.269 & 0.265 & 0.261 & 0.291 \\
\hline 10 & 1.034 & 0.753 & 0.663 & 0.659 & 0.675 & 0.639 & 0.645 & 0.488 & 0.465 & 0.288 & 0.272 & 0.284 \\
\hline $\mathrm{K}$ & &
\end{tabular}

N o t e : the highlighted cells indicate the plate wells / values where we observed increased turbidity and change in the color of the medium. 


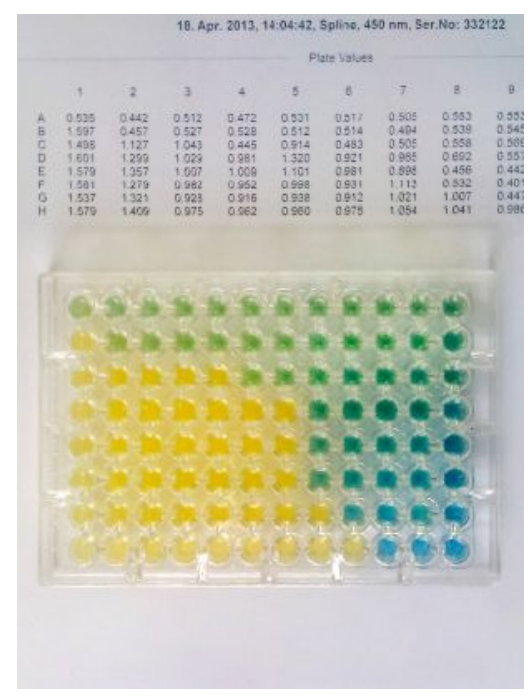

S. enteritidis

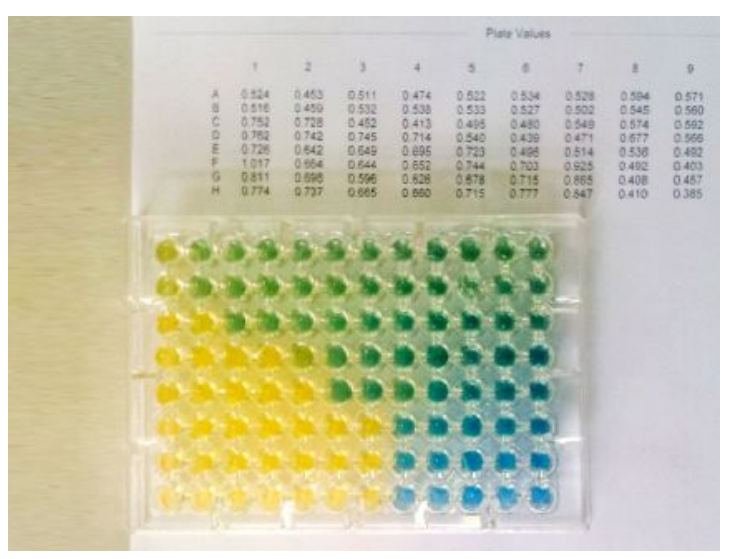

S. typhimurium

Figure 1. Growth of the salmonella collection strains in the experimental chromogenic model observed on the 96-well plate

Table 2

Degree of inhibition of $E$. coli test-strains under various concentration of active chlorine

\begin{tabular}{|c|c|c|c|c|c|c|c|c|}
\hline \multirow{2}{*}{ Strain №№ } & \multirow{2}{*}{$\begin{array}{c}\text { Reference } \\
\text { culture titer }\end{array}$} & \multicolumn{7}{|c|}{ Concentration of active chlorine in the medium, $\mathrm{mg} / \mathrm{dm}^{3}$} \\
\cline { 3 - 9 } & 8 & 200 & 150 & 100 & 75 & 50 & 25 & 10 \\
\hline $6 \kappa$ & 9 & 9 & 8 & 2 & 1 & 0 & 0 & 0 \\
\hline $14 \kappa$ & 9 & 8 & 3 & 2 & 1 & 2 & 2 & 0 \\
\hline $16 \kappa$ & 8 & 7 & 8 & 3 & 1 & 0 & 0 & 0 \\
\hline $2 \mathrm{\kappa} \kappa$ & 8 & 8 & 8 & 8 & 1 & 0 & 0 & 0 \\
\hline $23 \kappa$ & 9 & 8 & 6 & 1 & 0 & 1 & 1 & 1 \\
\hline $41 \kappa$ & 9 & 8 & 9 & 2 & 0 & 1 & 1 & 0 \\
\hline $49 \kappa$ & 11 & 10 & 10 & 4 & 4 & 3 & 3 & 0 \\
\hline $60 \kappa$ & 8 & 7 & 2 & 1 & 0 & 0 & 0 & 0 \\
\hline $62 \kappa$ & $8.78 \pm 0.32$ & $8.11 \pm 0.31$ & $6.89 \pm 0.90$ & $2.67 \pm 0.75$ & $1.11 \pm 0.42$ & $1.00 \pm 0.37$ & $0.89 \pm 0.35$ & $0.22 \pm 0.15$ \\
\hline $\begin{array}{c}(M) \pm \text { standard error } \\
\text { of the mean }\end{array}$ & 9.00 & 8.00 & 8.00 & 2.00 & 1.00 & 1.00 & 1.00 & 0.00 \\
\hline Median & & & & & & & \\
\hline
\end{tabular}

Microbiological studies of the plant raw materials and the sanitary conditions of food biotechnological manufacturing facilities included the assessment of quantitative levels of bacterial contamination, analysis of the species composition, study of the phenotypical properties of the isolated strains and their sensitivity to antimicrobial impact.

In the course of the analysis of the 13 samples of malt, grain and wipe from the brewing equipment, 32 cultures of gram-negative aerobic and optionally anaerobic bacteria were isolated and identified using a long list of culture-based and biochemical tests.

We identified 27 cultures from the total number of isolated strains; 26 strains belonged to $E n$ terobacteriaceae, 1 culture - to Pseudomonadoceae. The following bacteria were detected in the samples: Enterobacter, Pantoea, Citrobacter, Serratia, Pseudomonas, Klebsiella, Escherichia. From the total number of isolated strains, we determined the species for 17 cultures: E. amnigenus, E.aerogenes, Serratia fonticola, S.ficaria, Citrobacter freundii, Klebsiella pneumoniae, Escherichia coli, Pseudomonas aeruginosa.Analysis of the specific composition of the isolates showed that most strains were composed of Pantoea bacteria - 11 cultures (42\%). Pantoea microorganisms were found on most of the analyzed samples. The second most frequent group of microorganisms isolated from the swabs and raw materials included Enterobacter bacteria (29.6\% of all the strains). Sociological data about the detection rate of coliform lactosepositive bacteria and other gram-negative micro- 
organisms helped to reveal significant differences in the composition of the contaminants of raw materials and swabs: coliforms were more frequently found in the swabs, and enterobacteria - in the plant raw material - malt.

During the analysis of the species content of the microbial flora which contaminated starchcontaining raw materials for alcohol production (samples of whole and crushed wheat, barley, oats, potato tubers obtained from several regions of the Russian Federation, as well as imports, 17 samples total), we isolated 53 strains of gramnegative glucose-fermenting bacteria. At the conclusion of identification, association with the family Enterobacteriaceae was confirmed for 29 strains including potentially pathogenic bacteria of the Enterobacter, Pantoea, Citrobacter, Serratia, Escherichia classes.

Cronobacter microorganisms were isolated in two cases. The highest frequency of detection belonged to Enterobacter (38.0\%) and Pantoea (27. $6 \%$ ). Coliform lactose-positive bacteria (CGB) was found both in grain and potatoes, and enterobacte- ria of plant origin Pantoea spp was isolated only from grain raw materials.

The list of enterobacteria strains selected for the testing in the in vitro experimental chromogenic model is presented in Table 3.

The results of the comparative assessment of chlorine sensitivity of 26 strains isolated from plant raw materials and manufacturing equipment swabs are presented in Table 4.

Analysis of the obtained data revealed that all the tested enterobacteria strains were to one extent or another sensitive to the active chlorine concentrations used during the experiment. The concentration of 200 and $150 \mathrm{mg} / \mathrm{dm}^{3}$ fully suppressed the growth of 7 out of 26 tested strains $(26.9 \%)$. Active chlorine in the concentration of $75-100 \mathrm{mg} / \mathrm{dm}^{3}$ showed significant inhibition of the strain growth from $10^{8-9}$ cells $/ \mathrm{cm}^{3}$ to $10^{5-6}$ cells $/ \mathrm{cm}^{3}$, that is by 3,5-4,7 logarithmic order.A lower concentration of chlorine caused little inhibition - the density for the populations decreased only by 5-10 times (less than 1,0 lg cells $/ \mathrm{cm}^{3}$

Species associated of the enterobacteria strains under review

\begin{tabular}{|c|c|c|}
\hline Strain №№ & Species associated & Source of isolation \\
\hline \multicolumn{3}{|c|}{ Lactose-positive enterobacteria $(C G B)$} \\
\hline $5 / 6$ & Escherichia coli & Rye malt fermented \\
\hline 1 & Citrobacter freundii & Wheat \\
\hline $6 / 4$ & Citrobacter freundii & Wipe (dispensing machine) \\
\hline 24 & Citrobacter freundii & Wheat \\
\hline 50 & Citrobacter braakii & Potatoes \\
\hline $1 / 3$ & Klebsiella pneumonia & Malt barley \\
\hline 14 & Enterobacter spp & Wheat \\
\hline $7 / 4$ & Enterobacter cloacae & Rinse with dispenser (capping) \\
\hline $7 / 6$ & Enterobacter cloacae & Rinse with dispenser (capping) \\
\hline 16 & Enterobacter cloacae & Oats \\
\hline 22 & Enterobacter cloacae & Wheat \\
\hline 41 & Enterobacter cloacae & Potatoes \\
\hline 48 & Enterobacter cloacae & Potatoes \\
\hline 52 & Enterobacter cloacae & potatoes \\
\hline 47 & Cronobacter spp (E. sakazakii) & Potatoes \\
\hline 51 & Cronobacter spp (E. sakazakii) & Potatoes \\
\hline \multicolumn{3}{|c|}{ Lactose-negative enterobacteria } \\
\hline $2 / 1$ & Pantoea spp. & Rye \\
\hline $2 / 3$ & Pantoea spp. & Rye \\
\hline $3 / 1$ & Pantoea spp. & wheat Malt \\
\hline 20 & Pantoea spp & Barley \\
\hline 30 & Pantoea spp & Wheat \\
\hline 33 & Pantoea spp & Wheat \\
\hline 38 & Serratia ficaria & Potatoes \\
\hline 45 & Serratia marcescens & Potatoes \\
\hline 35 & Leclercia adecarboxylata & Wheat \\
\hline \multicolumn{3}{|c|}{ Other lactose-negative bacteria } \\
\hline $6 / 6$ & Pseudomonas aeruginosa & Wipe (dispensing machine) \\
\hline
\end{tabular}


Table 4

The degree of inhibition of strains isolated from plant raw materials and swabs $(\Delta i)$

\begin{tabular}{|c|c|c|c|c|c|c|c|c|}
\hline \multirow{2}{*}{ Strain №№ } & \multirow{2}{*}{$\begin{array}{c}\text { Reference } \\
\text { culture titer }\end{array}$} & \multicolumn{7}{|c|}{ Concentration of active chlorine in the medium, $\mathrm{mg} / \mathrm{dm}^{3}$} \\
\hline & & 200 & 150 & 100 & 75 & 50 & 25 & 10 \\
\hline \multicolumn{9}{|c|}{ Lactose-positive enterobacteria (CGB) } \\
\hline $5 / 6$ & 9 & 9 & 9 & 6 & 2 & 2 & 0 & 0 \\
\hline 1 & 9 & 9 & 9 & 8 & 8 & 3 & 2 & 1 \\
\hline $6 / 4$ & 9 & 8 & 8 & 6 & 1 & 1 & 0 & 0 \\
\hline 24 & 9 & 9 & 9 & 8 & 9 & 1 & 2 & 0 \\
\hline 50 & 8 & 7 & 7 & 2 & 1 & 1 & 0 & 0 \\
\hline $1 / 3$ & 8 & 7 & 7 & 6 & 6 & 0 & 0 & 0 \\
\hline 14 & 9 & 9 & 8 & 7 & 7 & 1 & 0 & 0 \\
\hline $7 / 4$ & 9 & 8 & 7 & 5 & 3 & 1 & 1 & 0 \\
\hline $7 / 6$ & 9 & 7 & 7 & 6 & 5 & 1 & 0 & 0 \\
\hline 16 & 11 & 10 & 11 & 9 & 10 & 3 & 2 & 2 \\
\hline 22 & 10 & 10 & 10 & 8 & 7 & 3 & 0 & 2 \\
\hline 41 & 9 & 8 & 6 & 0 & 0 & 0 & 1 & 0 \\
\hline 48 & 9 & 7 & 0 & 1 & 1 & 1 & 0 & 1 \\
\hline 52 & 10 & 9 & 8 & 2 & 2 & 0 & 2 & 2 \\
\hline 47 & 8 & 6 & 6 & 1 & 1 & 0 & 1 & 0 \\
\hline 51 & 8 & 7 & 7 & 1 & 1 & 0 & 0 & 0 \\
\hline $2 / 1$ & 9 & 7 & 7 & 6 & 5 & 1 & 0 & 0 \\
\hline $\begin{array}{l}(M) \pm \text { standard } \\
\text { error of the mean }\end{array}$ & $9.00 \pm 0.19$ & $8.06 \pm 0.29$ & $7.41 \pm 0.57$ & $4.82 \pm 0.72$ & $4.06 \pm 0.79$ & $1.12 \pm 0.26$ & $0.65 \pm 0.21$ & $0.47 \pm 0.19$ \\
\hline Median & 9.0 & 8.0 & 7.0 & 6.0 & 3.0 & 1.0 & 0.0 & 0.0 \\
\hline \multicolumn{9}{|c|}{ Lactose-negative enterobacteria and Pseudomonas spp. } \\
\hline $2 / 3$ & 9 & 8 & 8 & 7 & 7 & 3 & 1 & 1 \\
\hline $3 / 1$ & 8 & 7 & 7 & 5 & 3 & 2 & 0 & 0 \\
\hline 20 & 9 & 9 & 9 & 9 & 6 & 2 & 1 & 0 \\
\hline 30 & 8 & 8 & 8 & 2 & 2 & 1 & 1 & 1 \\
\hline 33 & 8 & 7 & 8 & 1 & 1 & 1 & 0 & 0 \\
\hline 38 & 8 & 7 & 3 & 0 & 0 & 0 & 0 & 0 \\
\hline 45 & 8 & 7 & 6 & 0 & 0 & 0 & 0 & 0 \\
\hline 35 & 7 & 7 & 4 & 2 & 1 & 1 & 1 & 0 \\
\hline $6 / 6$ & 8 & 3 & 2 & 0 & 0 & 0 & 0 & 0 \\
\hline $\begin{array}{l}(M) \pm \text { standard } \\
\text { error of the mean }\end{array}$ & $8.11 \pm 0.20$ & $7.00 \pm 0.55$ & $6.11 \pm 0.84$ & $2.89 \pm 1.11$ & $2.22 \pm 0.88$ & $1.11 \pm 0.35$ & $0.44 \pm 0.18$ & $0.22 \pm 0.15$ \\
\hline Median & 8.0 & 7.0 & 7.0 & 2.0 & 1.0 & 1.0 & 0.0 & 0.0 \\
\hline $\begin{array}{l}(M)^{*} \pm \text { standard } \\
\text { error of the mean }\end{array}$ & $8,69 \pm 0,22$ & $7,80 \pm 0,22$ & $6,94 \pm 0,42$ & $3,77 \pm 0,51$ & $2,83 \pm 0,50$ & $1,09 \pm 0,18$ & $0,66 \pm 0,14$ & $0,34 \pm 0,11$ \\
\hline Median & 9,0 & 8.00 & 8.00 & 2.00 & 1.00 & 1.00 & 0.00 & 0.00 \\
\hline
\end{tabular}

* - average value for all the tested strains.

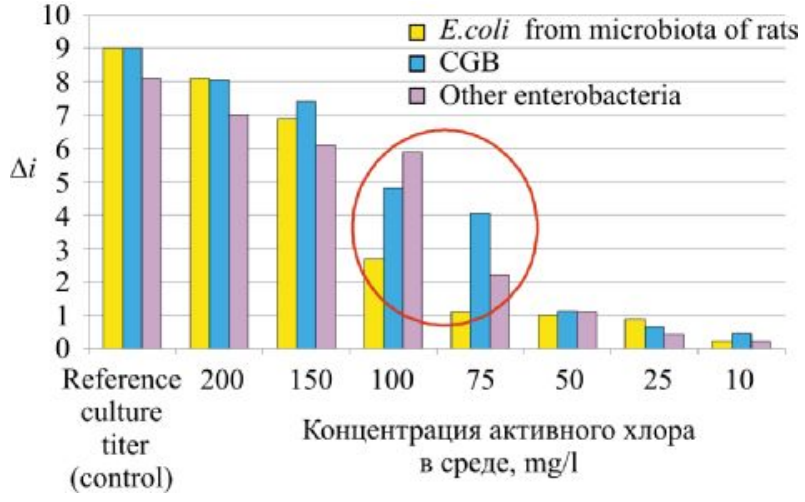

Figure 2. The degree of tolerance to chlorine in E.coli and enterobacteria isolated from swabs and plant raw materials
The comparison of chlorine sensitivity between Enterobacteriaceae bacteria isolated from swabs and plant raw material and E.coli strains from intestines showed that under the chlorine concentration of $75-100 \mathrm{mg} / \mathrm{dm}^{3}$, the bacteria isolated from plant raw material were less sensitive to the antimicrobial power of chlorine-containing products (Figure 2).

Pantoea enterobacteria demonstrated the highest tolerance to chlorine. This enterobacteria normally persists in the biotypes of plant and soil ecological systems and is one of the most common representatives of the family Enterobacteriaceae [2]. For example, the Pantoea spp. strains № 30 and № 35 iso- 
lated from wheat grain were resistant to active chlorine in the concentration of $100-150 \mathrm{mg} / \mathrm{dm}^{3}$, the degree of inhibition under theswe conditions was by 3 logarithmic orders lower as compared to other isolated strains (Table 4, Figure 3).

Chlorine sensitivity of coliform bacteria (CGB) isolated from plant raw materials as compared to other representatives of the family Enterobacteriaceae was more expressed in some cases, however we were not able to reveal significant difference given a small sample size.

The current practice of drinking water decontamination implies that the selected quantity of active chlorine meet the sanitary regulations and standards (SanPiN) 2.1.4.1074-01[ 3 ], at the same time the content of residual chlorine shall not exceed $0,3-0,5 \mathrm{mg} / \mathrm{dm}^{3}$. For these purposes, the most common concentration of active chlorine is from 50 to $100 \mathrm{mg} / \mathrm{dm}^{3}$ under various length of treatment (exposure).

In our experiment, active chlorine in the concentration of $100 \mathrm{mg} / \mathrm{dm}^{3}$ in the model environment decreased the density of bacterial populations on average by 5 logarithmic orders, and in the concentration of $75 \mathrm{mg} / \mathrm{dm} 3$ - by 3-4 orders. Exception here is Ps. aeruginosa 6/6 strain isolated from the equipment swabs: inhibition of the culture could be reached only when exposed to active chlorine in the concentration of $150-200 \mathrm{mg} / \mathrm{dm}^{3}$; the strains showed almost zero sensitivity to lower concentrations.

\section{Conclusions}

1. We studied the species composition of microbial contaminants of the plant raw materials and equipment used in the production of biotechnological products and fermented drinks; we isolated and studied using a series of culture-based and biochemical indicators 85 enterobacteria cultures of which we were able to identify the species of 46 strains of the classes Enterobacter, Pantoea, Citrobacter, Serratia, Escherichia, Cronobacter. Representatives of the classes Enterobacter and Pantoea were detected most frequently (approx.. 50\%).

2. We developed and tested experimentally a chromogenic model in vitro based on a display test-system that allows conducting a quantitative assessment of the degree of inhibition of gramnegative microbial flora impacted by antimicrobial products depending on the concentration of biocides and density of bacterial populations.

3. Using the developed model, we conducted a comparative analysis of the tolerance of enterobacteria strains isolated from various biotopes; we

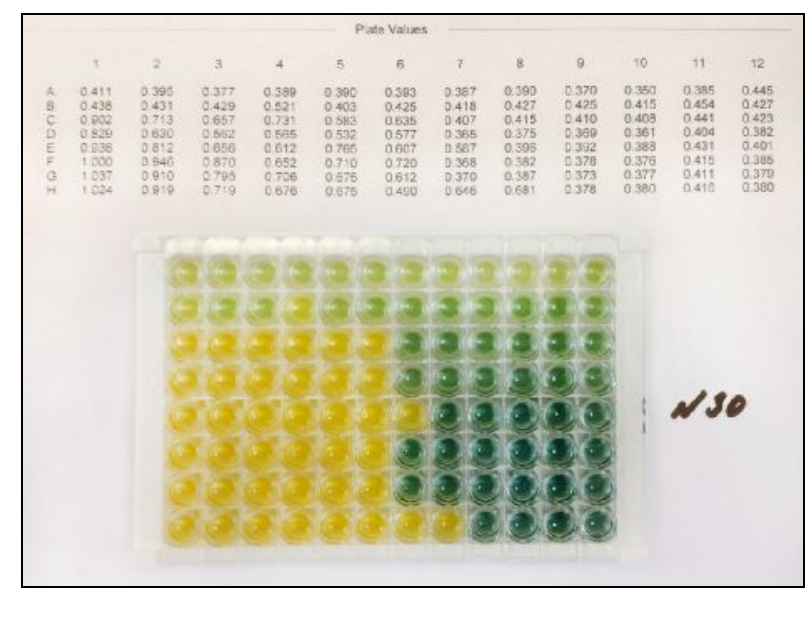

$a$

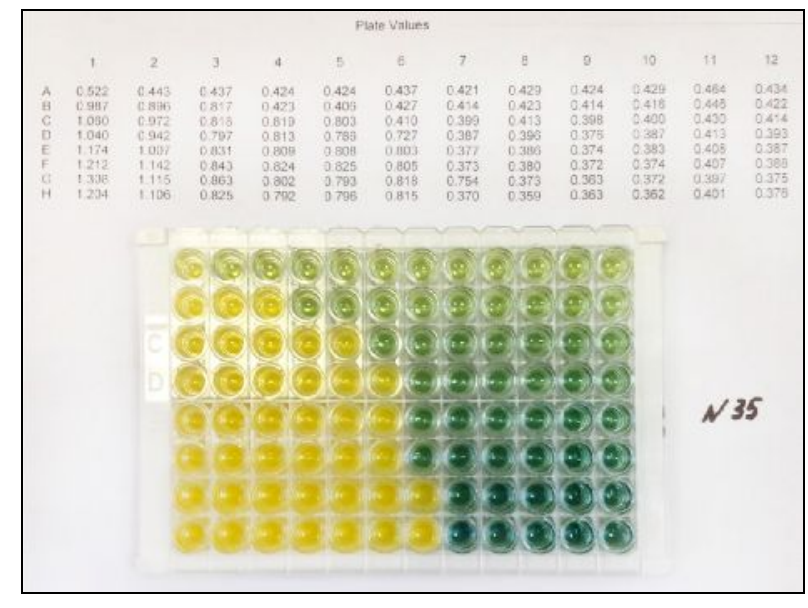

6

Figure 3. The growth of Pantoea spp. in the chromogenic model exposed to various concentration of active chlorine

tested sensitivity of 26 strains - contaminants of plant raw materials and 9 E.coli strains isolated from the intestines of laboratory animals - to chlorine-containing biocidal products. Enterobacteria from plant raw materials and swabs were most resistant to the antimicrobial power of chlorine as compared to the representatives of the population of normal intestine microbiota.

4. It was revealed that active chlorine in the concentration of $50-100 \mathrm{mg} / \mathrm{dm}^{3}$ most commonly used in the treatment of plant raw materials is not effective against the family Enterobacteriaceae if the density of the microbial population is higher than $10^{5-7}$ cells $/ \mathrm{cm}^{3}$. If the reference level of enterobacteria contamination is below $10^{3}$ cells $/ \mathrm{cm}^{3}$, then treatment with solutions containing active chlorine in the concentration of $75-100 \mathrm{mg} / \mathrm{dm}^{3}$ may effectively decontaminate raw materials and equipment. 
5. Experimental chromogenic model in vitro proposed for conducting the inhibition effect of chlorine-containing products on enterobacteria may be used to validate and select the concentrations of working solutions of antimicrobial prod- ucts that are effective against other groups of microbial contaminants which will provide for a more efficient use of the disinfecting modes for raw materials and sanitary treatment of equipment in the food industry.

\section{References}

1. Efimochkina N.R. Mikrobiologija pishhevyh produktov i sovremennye metody detekcii patogenov [Food microbiology and modern methods of detection of foodborne pathogens]. Moscow: Publishing house of the Russian Academy of Medical Sciences, 2013. 517 p.

2. Efimochkina N.R., Bykova I.B., Batisheva S.Yu., Minaeva L.P., Markova Yu.M., KorotkevichYu.V., Shilov G.Yu., ShevelevaS.A. Izuchenie osobennostej mikrobnoj kontaminacii svezhih ovoshhej i listovyh salatov promyshlennogo izgotovlenija [Study of microbial contamination of processed fresh vegetables and lettuce]. Voprosi pitanya, 2014, no. 5, pp. 33-42 (In Russan).

3. SanPiN 2.1.4.1074-01. «Pit'evaja voda. Gigienicheskie trebovanija k kachestvu vody centralizovannyh sistem pit'evogo vodosnabzhenija. Kontrol' kachestva. Gigienicheskie trebovanija k obespecheniju bezopasnosti sistem gorjachego vodosnabzhenija. Sanitarno-jepidemiologicheskie pravila i normativy» [SanPin 2.1.4.1074-01 «Drinking water. Hygienic requirements to water quality of centralized drinking water supply systems. Quality control. Hygienic requirements for safety of hot water systems. Sanitary-epidemiological rules and regulations»]. Moscow: Rospotrebnadzor, 2001 (In Russan).

4. Christian M.S., York R.G., Hoberman, A.M. et al. Biodisposition of dibromoacetic acid (DBA) and bromodichloromethane (BDCM) administered to rats and rabbits in drinking water during range-finding reproduction and developmental toxicity studies. International Journal of Toxicology, 2001, vol. 20, pp. 239-253.

5. Christian M.S., York R.G., Hoberman A.M. et al. Oral (drinking water) developmental toxicity studies of bromodichloromethane (BDCM) in rats and rabbits. International Journal of Toxicology, 2001, vol. 20, pp. 225-237.

6. Christian M.S., York R.G., Hoberman A.M. et al. Oral (drinking water) two-generation reproductive toxicity study of bromodichloromethane (BDCM) in rats. International Journal of Toxicology, 2002, vol. 21, pp. 115-146.

7. Hicks S.J., Rowbury R.J. Resistance of attached Escherichia coli to acrylic acid and its significance for the survival of plasmid-bearing organisms in water. Ann. Inst. Pasteur, 1987, vol.138, pp. 359-369.

8. International Life Sciences Institute. An Evaluation of EPA's Proposed Guidelines for Carcinogen Risk Assessment Using Chloroform and Dichloroacetate as Case Studies. Report of an Expert Panel, November 1997.

9. Mohyla P., Bilgili S. F., Oyarzabal O. A. et al. Application of Acidified Sodium Chlorite in the Drinking Water to Control Salmonella serotype Typhimurium and Campylobacter jejuni in Commercial Broilers. J. Appl. Poult Res., 2007, vol. 16, no. 1, pp. 45-51. doi: 10.1093/japr/16.1.45

10. Oyarzabal O.A. Reduction of Campylobacter spp. by commercial antimicrobials applied during the processing of broiler chickens: a review from the United States perspective. J. Food Prot., 2005, vol. 68, pp. 1752-1760.

11. Scientific Opinion of the Panel on Biological Hazards on a request from DG SANCO on the assessment of the possible effect of the four antimicrobial treatment substances on the emergence of antimicrobial resistance. The EFSA Journal, 2008, vol. 659, pp. 1-26

12. Whiting G.C., Rowbury R.J. Increased resistance of Escherichia coli to acrylic acid and to copper ions after cold-shock. Letts. Appl. Microbiol., 1995, vol. 20, pp. 240-242;

13. Yang, H., Li, Y. Johnson, M.G. Survival and death of Salmonella typhimurium and Campylobacter jejuni in processing water and on chicken skin during poultry scalding and chilling. J. Food Prot., 2001, vol. 64, pp. 770-776. 